\title{
MicroRNA-186-5p downregulation inhibits osteoarthritis development by targeting MAPK1
}

\author{
QING LI ${ }^{1}$, MINGJIE WU ${ }^{1}$, GUOFANG FANG ${ }^{1}$, KUANGWEN LI $^{1}$, WENGANG CUI ${ }^{1}$, \\ LIANG LI $^{1}$, XIA $\mathrm{LI}^{2}$, JUNSHENG WANG ${ }^{2}$ and YANHONG CANG ${ }^{2}$ \\ ${ }^{1}$ Department of Orthopedics, Shenzhen Hospital of Southern Medical University, Shenzhen, Guangdong 518101; \\ ${ }^{2}$ Department of Orthopedics, The Second People's Hospital of Huai'an, Huai'an, Jiangsu 223002, P.R. China
}

Received February 26, 2020; Accepted September 11, 2020

DOI: $10.3892 / \mathrm{mmr} .2021 .11892$

\begin{abstract}
As a chronic degenerative joint disease, the characteristics of osteoarthritis (OA) are degeneration of articular cartilage, subchondral bone sclerosis and bone hyperplasia. It has been reported that microRNA (miR)-186-5p serves a key role in the development of various tumors, such as osteosarcoma, non-small-cell lung cancer cells, glioma and colorectal cancer. The present study aimed to investigate the effect of miR-186-5p in OA. Different concentrations of IL- $1 \beta$ were used to treat the human chondrocyte cell line CHON-001 to simulate inflammation, and CHON-001 cell injury was assessed by detecting cell viability, apoptosis, caspase-3 activity and the levels of TNF- $\alpha$, IL-8 and IL-6. Subsequently, reverse transcription-quantitative PCR was performed to measure miR-186-5p expression. The results demonstrated that following IL-1 $\beta$ treatment, $\mathrm{CHON}-001$ cell viability was suppressed, apoptosis was promoted, the caspase-3 activity was significantly enhanced and the release of TNF- $\alpha$, IL- 8 and IL- 6 was increased. In addition, IL-1 $\beta$ treatment significantly upregulated miR-186-5p expression in CHON-001 cells. It was also identified that MAPK1 was a target gene of miR-186-5p, and was negatively regulated by miR-186-5p. miR-186 inhibitor and MAPK1-small interfering RNA (siRNA) were transfected into $\mathrm{CHON}-001$ cells to investigate the effect of miR-186-5p on CHON-001 cell injury induced by IL-1 $\beta$. The results demonstrated that miR-186 inhibitor suppressed the effects of IL-1 $\beta$ on CHON-001 cells, and these effects were reversed by MAPK1-siRNA. In conclusion, the present results indicated that miR-186-5p could attenuate IL-1 $\beta$-induced chondrocyte inflammation damage by increasing MAPK1
\end{abstract}

Correspondence to: Dr Xia Li or Dr Junsheng Wang, Department of Orthopedics, The Second People's Hospital of Huai'an, 62 Huaihai South Road, Huai'an, Jiangsu 223002, P.R. China

E-mail: pp8888789@163.com

E-mail:nnn2222345@163.com

Key words: osteoarthritis, microRNA-186-5p, inflammatory injury, chondrocytes expression, suggesting that $\mathrm{miR}-186-5 \mathrm{p}$ may be used as a potential therapeutic target for OA.

\section{Introduction}

As a chronic degenerative joint disease, the characteristics of osteoarthritis (OA) are degeneration of articular cartilage, subchondral bone sclerosis and bone hyperplasia (1). OA affects an estimated $10 \%$ of men and $18 \%$ of women $>60$ years of age, worldwide (2). OA is affected by multiple factors, such as age, sex, trauma history, obesity, heredity and joint deformity (3). At present, the pathogenesis of OA remains largely unknown. It is currently considered that the degeneration of articular cartilage in $\mathrm{OA}$ is due to a decrease in the number of chondrocytes, as well as a degradation of cartilage extracellular matrix stimulated by cytokines and growth factors (4). With the destruction of articular cartilage, the patient develops joint pain, stiffness and ultimately loss of mobility. Early drug relief symptoms and advanced joint replacement are the main treatments for OA (5). However, there are disadvantages, such as it is not applicable to all patients, and complications include instability, dislocation, infection, loosening, lysis and fracture, as well as adverse reactions to these treatments. Therefore, it is critical to investigate the molecular mechanisms underlying the development of OA and to provide markers of early OA diagnosis and bio-therapeutic targets.

MicroRNAs (miRNAs/miRs) are a class of non-coding short sequence RNAs of 18-25 nucleotides in length and without an open reading frame, which are widely found in eukaryotes (6). With the progress of research, the miRNA maturation process and its functional roles have gradually been identified. Incomplete base pairing between the miRNA and the 3'-untranslated region (3'-UTR) of the target mRNA can inhibit the expression of the target mRNA, and a complete complementary interaction between miRNA and target mRNA can result in mRNA degradation (7). miRNA also serves a regulatory role in the pathophysiology of human life, such as viral defense, cell proliferation and apoptosis, tumorigenesis, invasion and migration (8). Studies have reported that miRNAs serve key roles in maintaining homeostasis in the cartilage $(9,10)$. There is a significant difference of miRNA expression (such as miR-146a-5p, miR-140 and miR-27b) in chondrocytes between healthy individuals and patients with 
OA, which causes an imbalance of chondrocyte synthesis and catabolism that leads to the development of OA (11-13). These differentially expressed miRNAs may serve as predictive biomarkers for OA or potential targets for targeted therapies $(13,14)$.

miR-186-5p has been reported to be associated with numerous physiological processes, including migration, invasion, proliferation and inflammation, as well as the development of a number of diseases, such as cancer, ischemia stroke and diabetic cardiomyopathy (15-17). miR-186-5p has been studied in several malignancies, including non-small cell lung cancer (15), glioma (18), hepatocellular carcinoma (19), prostate cancer (20), lung adenocarcinoma (21), osteosarcoma (22) and ovarian cancer (23). A previous study revealed that miR-186 is downregulated in OA and its inhibition could block chondrocyte apoptosis in mice with OA (24). However, to the best of our knowledge, the role of miR-186-5p in OA development is yet to be fully elucidated.

The aim of the present study was to investigate the roles of miR-186-5p in the development of OA, as well as identify the potential molecular mechanisms involved, in order to provide a theoretical basis for OA treatment and a novel perspective for clinical therapy. Currently, IL-1 $\beta$-induced inflammatory injury has been widely used to investigate $\mathrm{OA}$ in vitro, and the human chondrocyte cell line $\mathrm{CHON}-001$ is often used to establish a model of chondrocyte inflammation injury (25-27). Thus, in the present study, the role of miR-186-5p in IL-1 $\beta$-induced CHON-001 cell inflammatory injury was examined, in order to evaluate the role of miR-186-5p in OA development.

\section{Materials and methods}

Cell culture and treatment. The human chondrocyte cell line CHON-001, derived from healthy human articular cartilage, was obtained from the American Type Culture Collection. Cells were cultured in DMEM (Gibco; Thermo Fisher Scientific, Inc.), supplemented with $0.1 \mathrm{mg} / \mathrm{ml} \mathrm{G}-418$ (Gibco; Thermo Fisher Scientific, Inc.) and 10\% FBS (Gibco; Thermo Fisher Scientific, Inc.), in a humidified atmosphere with $5 \% \mathrm{CO}_{2}$ at $37^{\circ} \mathrm{C}$ and passaged at a ratio of 1:5.

The recombinant human IL-1 $\beta$ (R\&D Systems, Inc.; 0.1, 2, 5 and $10 \mathrm{ng} / \mathrm{ml}$ ) was used to treat the $\mathrm{CHON}-001$ cells at $37^{\circ} \mathrm{C}$ for $12 \mathrm{~h}$ to induce cell inflammatory injury.

Cell transfection. $\mathrm{CHON}-001$ cells were transfected with $100 \mathrm{nM}$ miR-186-5p inhibitor (5'-AGCCCAAAAGGAGAA UUCUUUG-3'; Guangzhou RiboBio Co., Ltd.), 100 nM inhibitor control (5'-GCCUCCGGCUUCGCACCUCU-3'; Guangzhou RiboBio Co., Ltd.), $0.2 \mu \mathrm{M}$ MAPK1-small interfering RNA (siRNA; cat no. sc-35335; Santa Cruz Biotechnology, Inc.), $0.2 \mu \mathrm{M}$ control-siRNA (cat no. sc-36869; Santa Cruz Biotechnology, Inc.), 100 nM miR-186-5p inhibitor $+0.2 \mu \mathrm{M}$ control-siRNA or $100 \mathrm{nM}$ miR-186-5p inhibitor $+0.2 \mu \mathrm{M}$ MAPK1-siRNA, using Lipofectamine ${ }^{\circledR}$ 2000 (Invitrogen; Thermo Fisher Scientific, Inc.), according to the manufacturer's protocol. At $48 \mathrm{~h}$ post-transfection, reverse transcription-quantitative PCR (RT-qPCR) was performed to detect the transfection efficiency. A total of $24 \mathrm{~h}$ after cell transfection, the cells were subjected to treatment with
$10 \mathrm{ng} / \mathrm{ml} \mathrm{IL}-1 \beta$ at $37^{\circ} \mathrm{C}$ for $12 \mathrm{~h}$, and further experiments were then performed.

Cell viability assay. Cell viability was assessed using a Cell Counting Kit-8 (CCK-8; Dojindo Molecular Technologies, Inc.) assay according to the manufacturer's instructions. CHON-001 cells were seeded in a 96-well plate at a density of $5 \times 10^{3}$ cells per well. Following administration, the CCK-8 solution $(10 \mu \mathrm{l})$ was added to the culture medium, and cells were incubated for $1 \mathrm{~h}$ at $37^{\circ} \mathrm{C}$ in humidified $95 \%$ air and $5 \% \mathrm{CO}_{2}$. The absorbance was measured at $450 \mathrm{~nm}$ using a microplate reader (Bio-Rad Laboratories, Inc.).

Cell apoptosis assay. Cell apoptosis analysis was performed using an Annexin V-FITC and PI apoptosis detection kit (Beyotime Institute of Biotechnology) according to the manufacturer's instructions. Following treatment, cells $\left(10^{6}\right)$ were collected and washed in PBS. Cells were then suspended in binding buffer containing $10 \mu \mathrm{l}$ Annexin V-FITC and $5 \mu \mathrm{l}$ PI, which was followed by incubation for $1 \mathrm{~h}$ at room temperature in the dark. Flow cytometry analysis was performed using a FACScan flow cytometer (Beckman Coulter, Inc.) to detect cell apoptosis (the percentage of early + late apoptotic cells). Data were analyzed using FlowJo software (version 7.6.1; FlowJo LLC).

ELISA. ELISA was used to detect the levels of TNF- $\alpha$, IL-6 and IL- 8 in the supernatant of $\mathrm{CHON}-001$ cell culture medium. The supernatant of $\mathrm{CHON}-001$ cell culture medium was collected via centrifugation $\left(500 \mathrm{x} \mathrm{g} ; 5 \mathrm{~min} ; 4^{\circ} \mathrm{C}\right)$. ELISA kits (Beyotime Institute of Biotechnology) were used to detect TNF- $\alpha$ (cat. no. PT518), IL-6 (cat. no. PI330) and IL-8 (cat. no. PI640) release in the supernatant of cells, following the manufacturer's instructions of each kit. To calculate the corresponding concentration of the sample, the A450 value was detected using the FLUOstar ${ }^{\circledR}$ Omega Microplate reader (BMG Labtech GmbH) (28).

Determination of caspase-3 activity. Trypsin was used to detach the treated $\mathrm{CHON}-001$ cells from the culture medium. CHON-001 cells were collected via centrifugation $(600 \mathrm{x} \mathrm{g}$; $4^{\circ} \mathrm{C}$; $5 \mathrm{~min}$ ). Subsequently, caspase- 3 activity was determined using caspase-3 activity assay kit (Beyotime Institute of Biotechnology), according to the manufacturer's protocols. To evaluate the caspase-3 activity, the wavelength at $405 \mathrm{~nm}$ was detected using an automatic microplate reader (ELX800; BioTek Instruments Inc.). In total, one unit is the amount of enzyme that will cleave $1.0 \mathrm{nmol}$ of the colorimetric substrate Ac-DEVD-pNA [L-Asparagine,N-acetyl-L-a-aspartyl-L-a-gl utamyl-L-valyl-N-(4-nitrophenyl)-(9CI)] per $\mathrm{h}$ at $37^{\circ} \mathrm{C}$ under saturated substrate concentrations (29).

$R T$-qPCR. TRIzol ${ }^{\circledR}$ reagent (Invitrogen; Thermo Fisher Scientific, Inc.) was used to isolate the total RNA from treated CHON-001 cells, following the manufacturer's instructions. miScript II Reverse Transcription kit (Qiagen $\mathrm{GmbH}$ ) and miSCRIPT SYBR-Green PCR kit (Qiagen GmbH) were used to analyze miRNA expression as per the manufacturer's protocols. For mRNA detection, PrimeScript ${ }^{\mathrm{TM}}$ RT reagent kit (Takara Bio, Inc.) was used for RT, and then qPCR analysis was 
performed using the SYBR Premix Ex Taq ${ }^{\mathrm{TM}}$ II (Tli RNaseH Plus) kit (Takara Bio, Inc.), according to the manufacturer's protocol. The reaction conditions for RT were as follows: $70^{\circ} \mathrm{C}$ for $5 \mathrm{~min}, 37^{\circ} \mathrm{C}$ for $5 \mathrm{~min}$ and $42^{\circ} \mathrm{C}$ for $60 \mathrm{~min}$. The following thermocycling conditions were used for the qPCR: Initial denaturation for $5 \mathrm{~min}$ at $95^{\circ} \mathrm{C}$; followed by 37 cycles of denaturation at $95^{\circ} \mathrm{C}$ for $10 \mathrm{sec}$, annealing at $60^{\circ} \mathrm{C}$ for $30 \mathrm{sec}$ and extension at $72^{\circ} \mathrm{C}$ for $34 \mathrm{sec}$. U6 was used to normalize the expression of miR-186-5p, and GAPDH was used to normalize MAPK1 mRNA expression. The primer sequences used for the PCR were listed as follows: U6 forward, 5'-GCTTCGGCA GCACATATACTAAAAT-3' and reverse, 5'-CGCTTCACG AATTTGCGTGTCAT-3'; GAPDH forward, 5'-CTTTGG TATCGTGGAAGGACTC-3' and reverse, 5'-GTAGAGGCA GGGATGATGTTCT-3'; miR-186-5p forward, 5'-AAGAAT TCTCCTTTTGGGCT-3' and reverse, 5'-GTGCGTGTCGTG GAGTCG-3'; and MAPK1 forward, 5'-GTCGCCATCAAG AAAATCAGC-3', and reverse 5'-GGAAGGTTTGAGGTC ACGGT-3'. The $2^{-\Delta \Delta C q}$ method (30) was used to calculate the expression of target genes.

Dual-luciferase reporter gene assay. TargetScan 7.2 (http://www.targetscan.org/vert_72/) was used to predict the target of miR-186-5p, and the results suggested a binding site of miR-186-5p in the 3'-UTR of the MAPK1 gene. Subsequently, it was verified that MAPK1 was a target gene of miR-186-5p using the dual-luciferase reporter gene assay. The pmirGLO vector (1 ng; Promega Corporation) containing a mutant type or wild-type 3'-UTR of MAPK1 was co-transfected with the $100 \mathrm{nM}$ miR-186-5p mimic or $100 \mathrm{nM}$ mimic control into CHON-001 cells for $48 \mathrm{~h}$ using Lipofectamine ${ }^{\circledR}$ 2000 (Invitrogen; Thermo Fisher Scientific, Inc.), according to the manufacturer's protocol. The relative luciferase activity was measured using a Dual-Luciferase reporter assay system (Promega Corporation), according to the manufacturer's protocols. Luciferase activity was normalized to the Renilla luciferase activity.

Western blot analysis. RIPA lysis buffer (Beyotime Institute of Biotechnology) and protease inhibitor (Beyotime Institute of Biotechnology) were used to extract the proteins from cells. A BCA protein assay was then used to quantify the proteins. Equal amounts of protein ( $35 \mu \mathrm{g} /$ lane) were separated via $12 \%$ SDS-PAGE and then transferred to PVDF membranes. Subsequently, the membranes were blocked with 5\% non-fat milk at room temperature for $90 \mathrm{~min}$ and incubated with primary antibodies: MAPK1 (cat. no. ab205819; 1:1,000; Abcam) and GAPDH (cat. no. 5174; 1:1,000; Cell Signaling Technology, Inc.) at $4^{\circ} \mathrm{C}$ overnight. This was followed by incubation with anti-rabbit horseradish peroxidase-conjugated immunoglobulin G secondary antibody (cat no. 7074; 1:2,000; Cell Signaling Technology, Inc.) at room temperature for $2 \mathrm{~h}$. Finally, an enhanced chemiluminescence detection system (Applygen Technologies, Inc.) was used to observe the protein bands. For densitometry detection, analysis with Image J 1.38X software (National Institutes of Health) was performed.

Statistical analysis. All experiments were repeated three times, and data are presented as the mean \pm SD. GraphPad 6.0 (Graph Pad Software, Inc.) was used to perform the statistical analyses, and unpaired Student's t-test or one-way ANOVA with Tukey's post hoc test were used to analyze differences between groups. $\mathrm{P}<0.05$ was considered to indicate a statistically significant difference.

\section{Results}

IL-1 $\beta$ induces chondrocyte inflammatory injury and promotes miR-186-5p expression in vitro. Different concentrations of IL-1 $\beta(0.1,2,5$ and $10 \mathrm{ng} / \mathrm{ml})$ were used to treat human chondrocyte $\mathrm{CHON}-001$ cells for $12 \mathrm{~h}$. The results demonstrated that the treatments with 5 and $10 \mathrm{ng} / \mathrm{ml} \mathrm{IL-1 \beta}$ significantly decreased CHON-001 cell viability (Fig. 1A). Therefore, 5 and $10 \mathrm{ng} / \mathrm{ml} \mathrm{IL-1} \beta$ were used as the effective concentrations for the further experiments. Subsequently, cell apoptosis assay results suggested that the treatment with 5 and $10 \mathrm{ng} / \mathrm{ml}$ IL- $1 \beta$ significantly induced $\mathrm{CHON}-001$ cell apoptosis (Fig. 1B and C), as well as promoted the activity of caspase- 3 in $\mathrm{CHON}-001$ cells (Fig. 1D).

To confirm that treatment with IL-1 $\beta$ could induce the inflammatory response of CHON-001 cells, the levels of TNF- $\alpha$, IL- 8 and IL- 6 were then examined. It was found that following exposure to IL-1 $\beta$ ( 5 or $10 \mathrm{ng} / \mathrm{ml}$ ), the levels of TNF- $\alpha$, IL- 8 and IL- 6 were increased (Fig. 1E). These results indicated that treatment with IL-1 $\beta$ induced inflammatory injury of CHON-0001 cells. In addition, it was identified that the expression of miR-186-5p was significantly increased in IL-1 $\beta$-treated CHON-0001 cells at concentrations of 5 and $10 \mathrm{ng} / \mathrm{ml}$ (Fig. 1F).

MAPK1 is a target gene of $m i R-186-5 p$, and its expression is decreased significantly in chondrocytes treated with $I L-1 \beta$. Based on the information provided by TargetScan, binding sites between miR-186-5p and MAPK1 were identified (Fig. 2A), and then a Dual-Luciferase reporter gene assay was used to verify these results. miR-186-5p overexpression significantly decreased the luciferase activity of the wild-type MAPK1 3'-UTR reporter. However, miR-186-5p overexpression had no significant effect on the luciferase activity of the mutant MAPK1 3'-UTR reporter (Fig. 2B). Overall, these results suggested that MAPK1 was a direct target gene of miR-186-5p.

Subsequently, 5 and $10 \mathrm{ng} / \mathrm{ml}$ IL- $1 \beta$ was used to treat CHON-001 cells for $12 \mathrm{~h}$, and the expression of MAPK1 was detected using RT-qPCR and western blot analysis. It was demonstrated that 5 and $10 \mathrm{ng} / \mathrm{ml} \mathrm{IL-1} \beta$ significantly decreased the expression of MAPK1 in CHON-001 cells (Fig. 2C and D).

Inhibition of miR-186-5p decreases the chondrocyte inflammatory injury induced by $I L-1 \beta$. The effect of miR-186-5p inhibition on chondrocytes induced by IL-1 $\beta(10 \mathrm{ng} / \mathrm{ml})$ was then investigated. Inhibitor control, miR-186-5p inhibitor, MAPK1-siRNA, control-siRNA, miR-186-5p inhibitor + control-siRNA and miR-186-5p inhibitor + MAPK1-siRNA were transfected into CHON-001 cells. RT-qPCR results demonstrated that miR-186-5p inhibitor significantly decreased the expression of miR-186-5p in CHON-001 cells (Fig. 3A). MAPK1-siRNA significantly inhibited MAPK1 mRNA expression in CHON-001 cells (Fig. 3B). Furthermore, the miR-186-5p inhibitor significantly increased protein and 

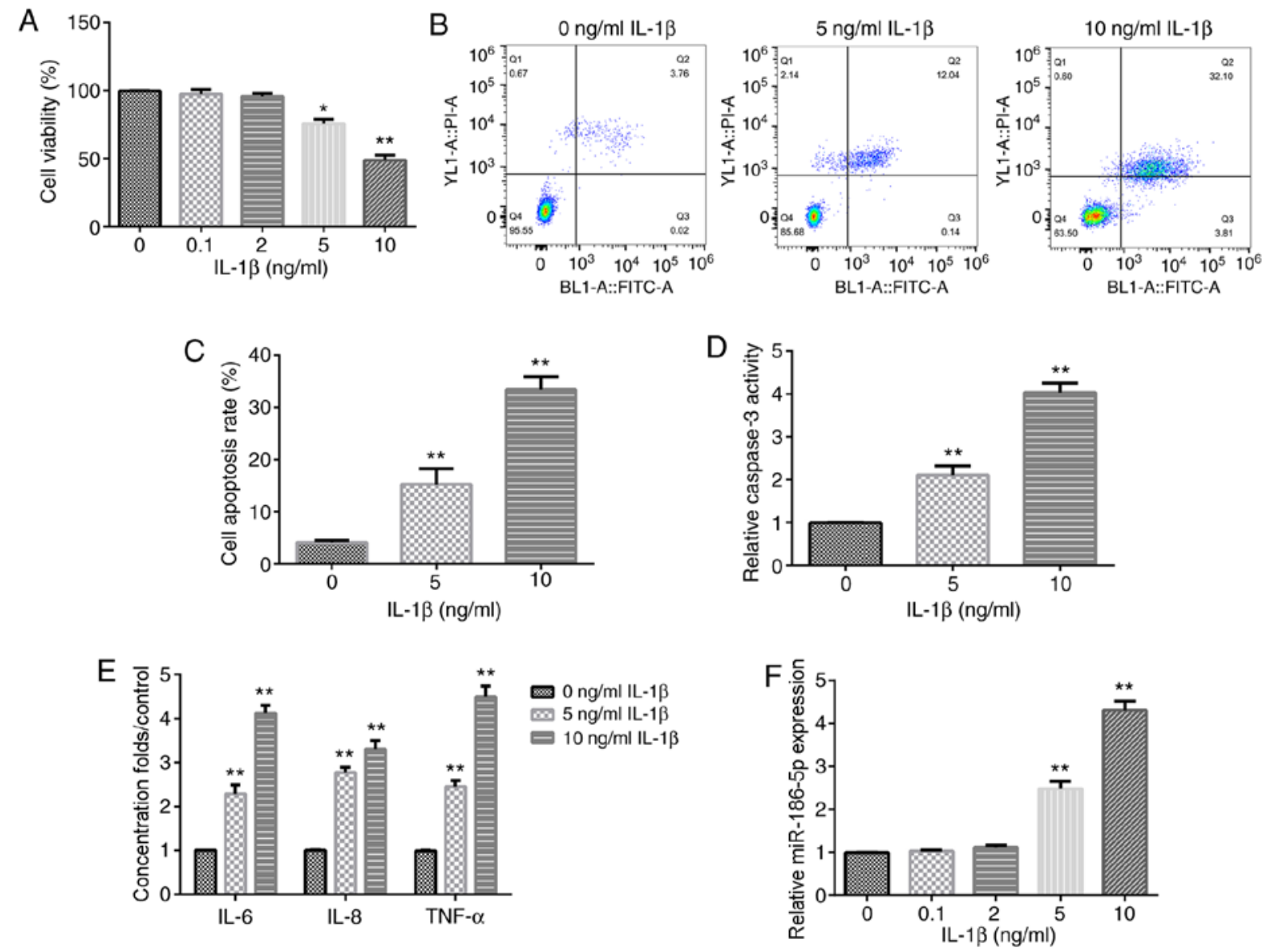

Figure 1. Effect of IL-1 $\beta$ on chondrocyte inflammation and miR-186-5p expression. Different concentrations of IL-1 $\beta(0.1,2,5 \mathrm{and} 10 \mathrm{ng} / \mathrm{ml})$ were used to treat CHON-001 cells for $12 \mathrm{~h}$, and then Cell Counting Kit-8 analysis was used to detect cell viability. (A) Effect of different concentrations of IL-1 $1 \beta$ on CHON-001 viability. (B) Flow cytometric analysis was used to examine the (C) effect of 5 and $10 \mathrm{ng} / \mathrm{ml} \mathrm{IL-1 \beta}$ on CHON-001 cell apoptosis. (D) Effect of 5 and $10 \mathrm{ng} / \mathrm{ml}$ IL-1 $\beta$ on the activity of caspase-3. (E) Effect of 5 and $10 \mathrm{ng} / \mathrm{ml}$ IL- $1 \beta$ on the levels of three inflammation cytokines, TNF- $\alpha$, IL- 8 and IL- 6 , was determined using ELISA. (F) Reverse transcription-quantitative PCR was used to detect the effect of IL-1 $\beta(0.1,2,5 \mathrm{and} 10 \mathrm{ng} / \mathrm{ml})$ on miR-186-5p expression. ${ }^{*} \mathrm{P}<0.05$, ${ }^{* * *} \mathrm{P}<0.01$ vs. $0 \mathrm{ng} / \mathrm{ml}$ IL-1 3 . miR-186-5p, microRNA-186-5p.

mRNA expression levels of MAPK1 in CHON-001 cells, which was reversed by MAPK1-siRNA (Fig. 3C and D).

Results of the cell viability assay demonstrated that, compared with the IL-1 $\beta(10 \mathrm{ng} / \mathrm{ml})$ treatment group, transfection with miR-186-5p inhibitor significantly increased cell viability (Fig. 4A), decreased cell apoptosis (Fig. 4B and C) and inhibited the activity of caspase-3 (Fig. 4D). All these changes were significantly reversed by MAPK1-siRNA (Fig. 4A-D).

Compared with the IL-1 $\beta(10 \mathrm{ng} / \mathrm{ml})$ treatment group, transfection with miR-186-5p inhibitor significantly decreased the release of IL-6 (Fig. 5A), IL-8 (Fig. 5B) and TNF- $\alpha$ (Fig. 5C) in CHON-001 cell culture medium, and this effect was significantly reversed by MAPK1-siRNA.

Finally, it was identified that, compared with the IL- $1 \beta$ (10 ng/ml) treatment group, miR-186-5p inhibitor transfection significantly increased the expression of MAPK1, which was significantly reversed by MAPK1-siRNA (Fig. 6).

\section{Discussion}

A key pathogenic factor of OA is inflammation; it has been reported that there is a positive correlation between OA severity and the expression of the pro-inflammatory cytokine IL-1 $\beta$ (31).
The present study established an OA model using CHON-001 chondrocytes induced by IL-1 $\beta$ in vitro. The results suggested that 5 and $10 \mathrm{ng} / \mathrm{ml}$ IL- $1 \beta$ could induce effects of cell inflammation, such as decreasing cell viability, as well as promoting cell apoptosis and the expression levels of inflammatory factors.

A previous study reported that miRNAs regulate 100 s of genes, such as ADAM metallopeptidase with thrombospondin type 1 motif 5, MMP-13 and insulin like growth factor binding protein 5) that are involved in homeostasis, cartilage development and OA pathology (32). Due to their ability to regulate cell apoptosis and reactive oxygen species, miRNAs serve important roles in the abnormal autophagy response of OA chondrocytes (33). Wu et al (33) reviewed numerous studies and revealed that $>25$ types of miRNAs are involved in the development of cartilage and OA, particularly in regulating proteolytic enzyme synthesis and chondrocyte hypertrophy. In addition, certain OA cartilage signal transduction pathways are regulated by miRNAs, such as the TGF- $\beta$, bone morphogenetic protein family, inducible nitric oxide synthase IL-1, MMP and TNF- $\alpha$ pathways (34). Cong et al (35) reviewed published reports and reported that numerous miRNAs are differentially expressed in OA, where upregulated miRNAs are mainly involved in biological processes occurring in the 

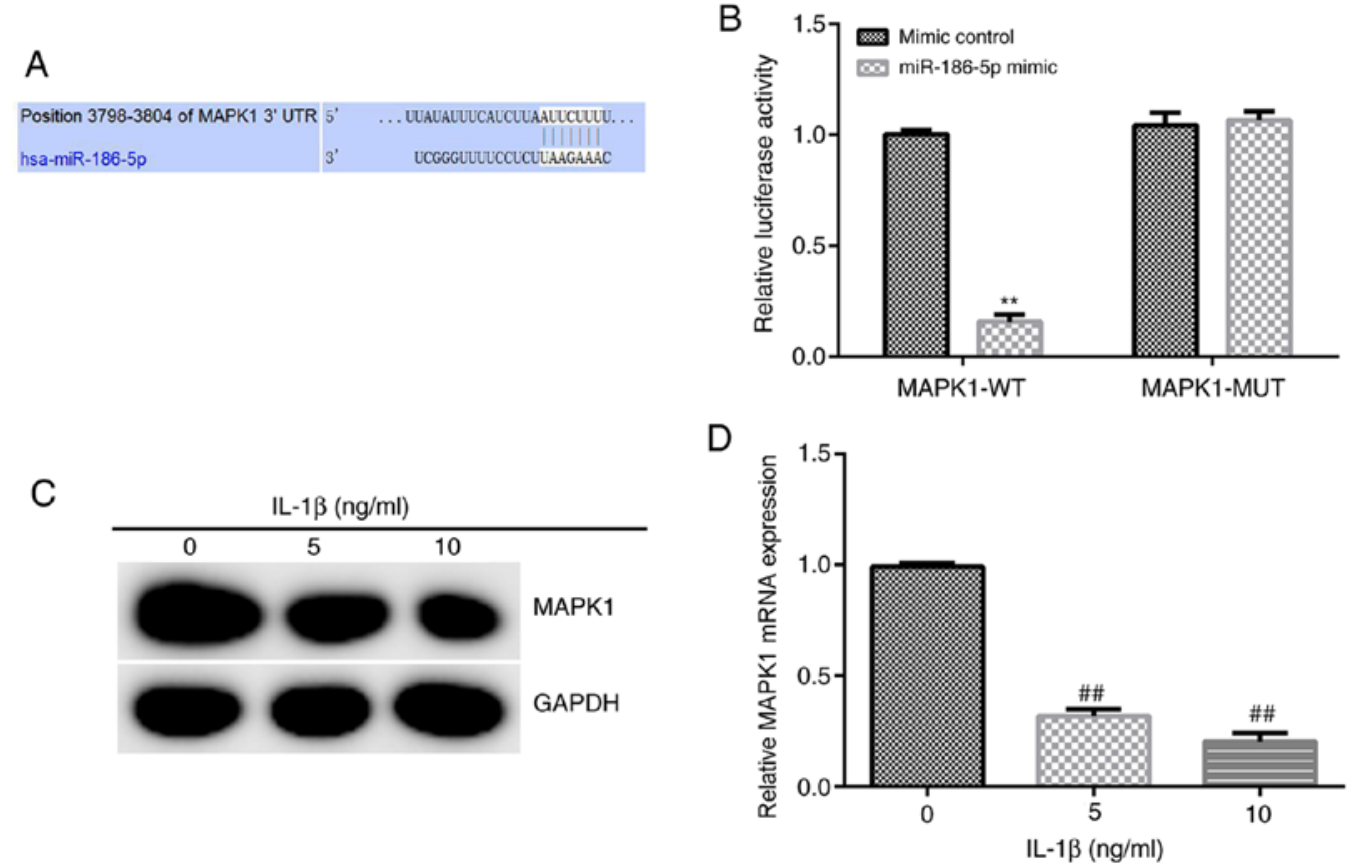

Figure 2. MAPK1 is a target gene of miR-186-5p, and the expression of MAPK1 in chondrocytes is induced by IL-1 $\beta$. (A) TargetScan was used to predict, and (B) Dual-Luciferase reporter gene assay was used to verify the target gene of miR-186-5p. (C) Western blotting and (D) reverse transcription-quantitative PCR were used to detect MAPK expression in chondrocytes induced by IL-1 $\beta$. ${ }^{* *} \mathrm{P}<0.01$ vs. mimic control; ${ }^{\# \#} \mathrm{P}<0.01 \mathrm{vs}$. $0 \mathrm{ng} / \mathrm{ml} \mathrm{IL}-1 \beta$. miR-186-5p, microRNA-186-5p; WT, wild-type; MUT, mutant; UTR, untranslated region.
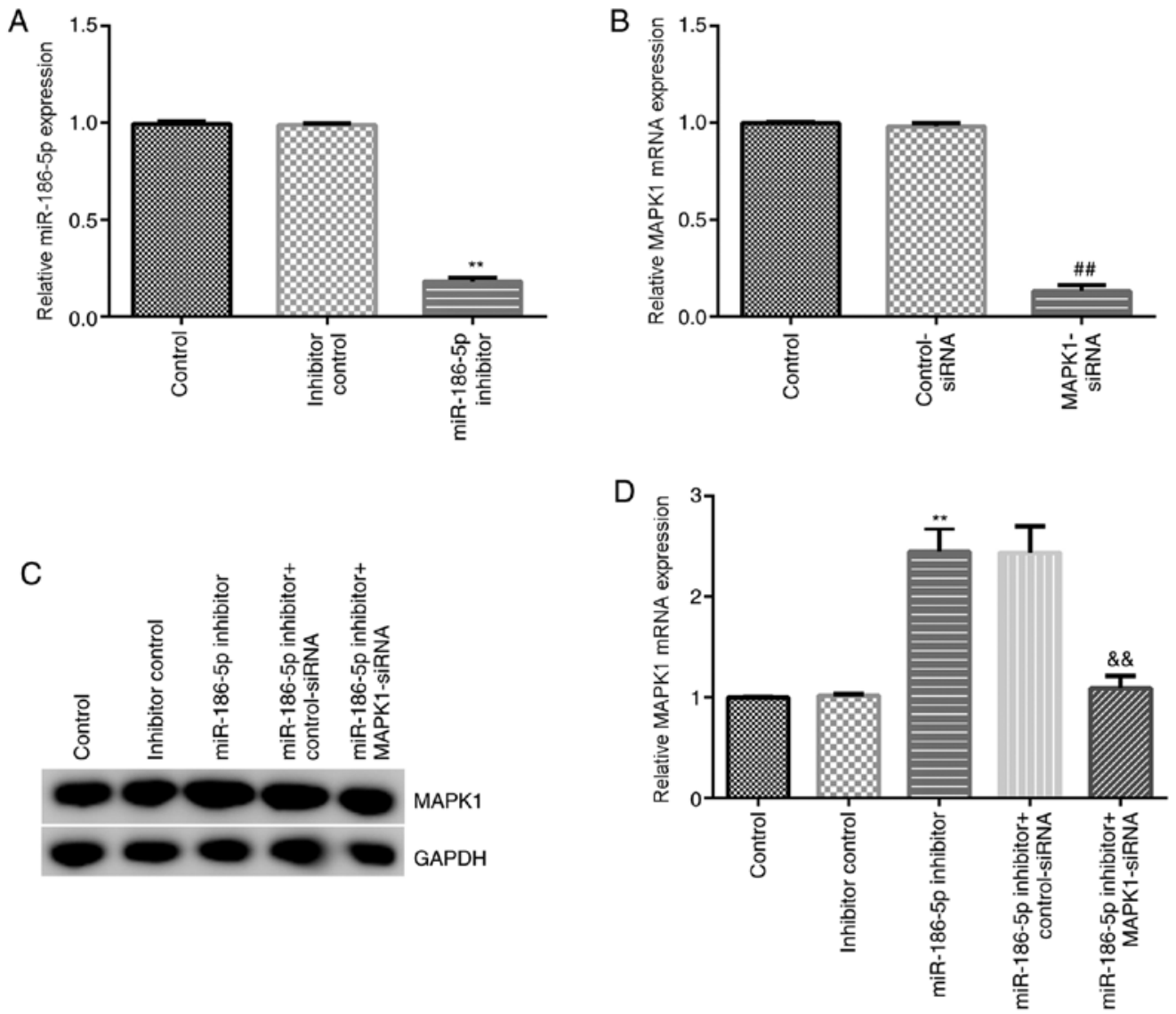

Figure 3. Effect of miR-186-5p on MAPK1 expression in CHON-001 cells. Inhibitor control, miR-186 inhibitor, MAPK1-siRNA, control-siRNA, miR-186 inhibitor + control-siRNA and miR-186 inhibitor + MAPK1-siRNA were transfected into CHON-001 cells for $48 \mathrm{~h}$, and then reverse transcription-quantitative PCR was performed to detect the mRNA expression levels of related gene. (A) Effect of miR-186 inhibitor on the expression of miR-186 in CHON-001 cells. (B) Effect of MAPK1-siRNA on MAPK1 mRNA expression in CHON-001 cells. effects of miR-186 inhibitor and MAPK1-siRNA on MAPK1 (C) protein and (D) mRNA expression in CHON-001 cells. ${ }^{* *} \mathrm{P}<0.01$ vs. inhibitor control; ${ }^{\# \#} \mathrm{P}<0.01$ vs. control-siRNA; ${ }^{\& \&} \mathrm{P}<0.01$ vs. miR-186 inhibitor + control-siRNA miR-186-5p, microRNA-186-5p; siRNA, small interfering RNA. 

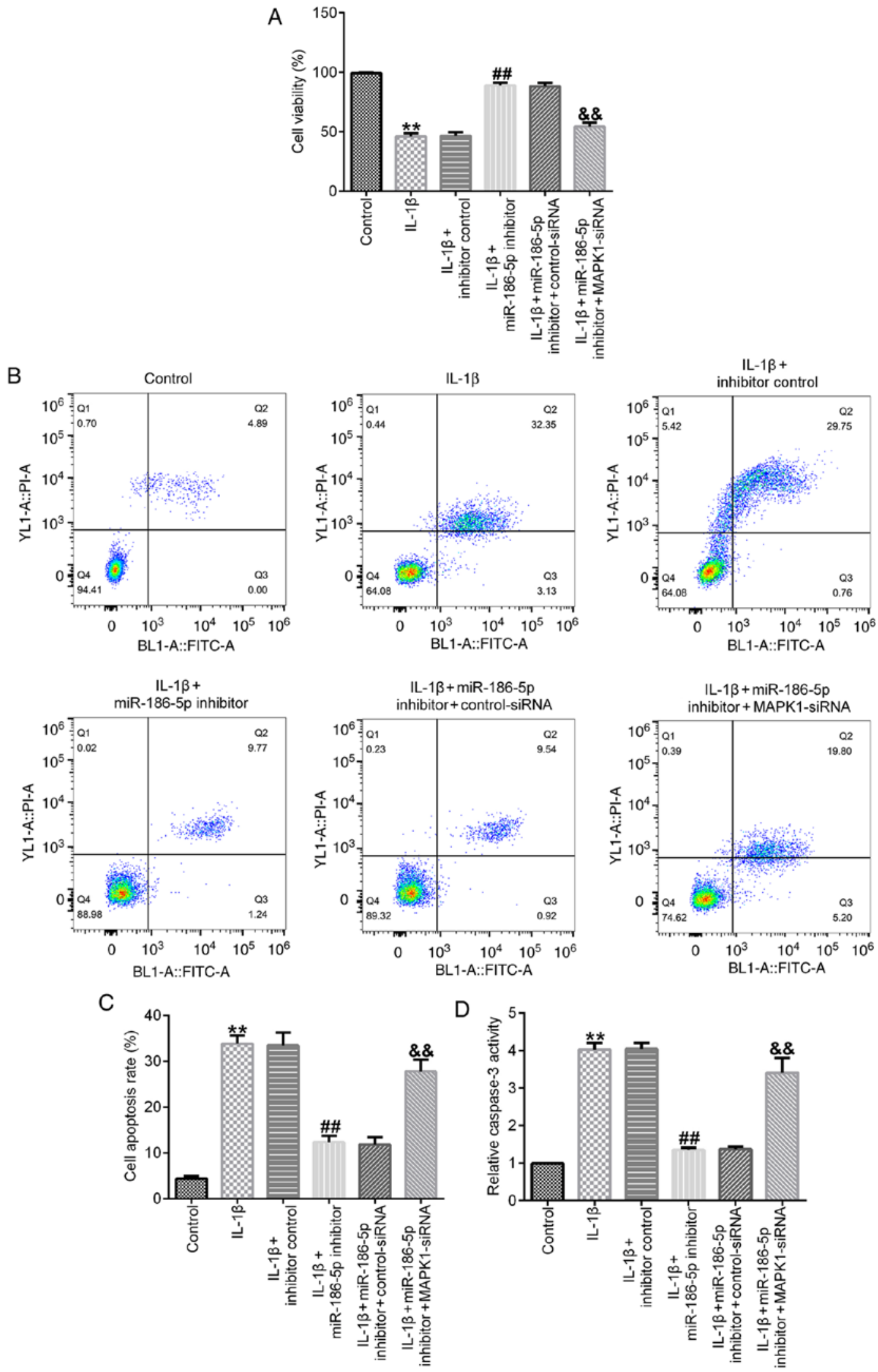

Figure 4. Effect of miR-186-5p inhibitor on IL-1 $\beta$-induced-chondrocyte apoptosis. IL-1 $(10 \mathrm{ng} / \mathrm{ml})$ was used to treat the transfected chondrocytes for $12 \mathrm{~h}$.

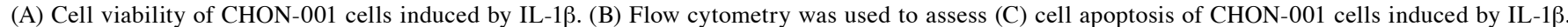
(D) Activity of caspase-3 in CHON-001 cells induced by IL-1 $\beta .{ }^{* *} \mathrm{P}<0.01$ vs. Control; ${ }^{* \#} \mathrm{P}<0.01$ vs. IL-1 $\beta+$ inhibitor control; ${ }^{\text {\& }} \mathrm{P}<0.01$ vs. IL-1 $\beta+$ miR-186 inhibitor + control-siRNA. miR-186-5p, microRNA-186-5p; siRNA, small interfering RNA.

nucleus, and downregulated miRNAs are primary involved in the transcriptional process, indicating that miRNAs exert key roles in the beginning and development of OA. Specifically, miR-140, miR-9, miR-34a, miR-558, miR-27, miR-602 and 

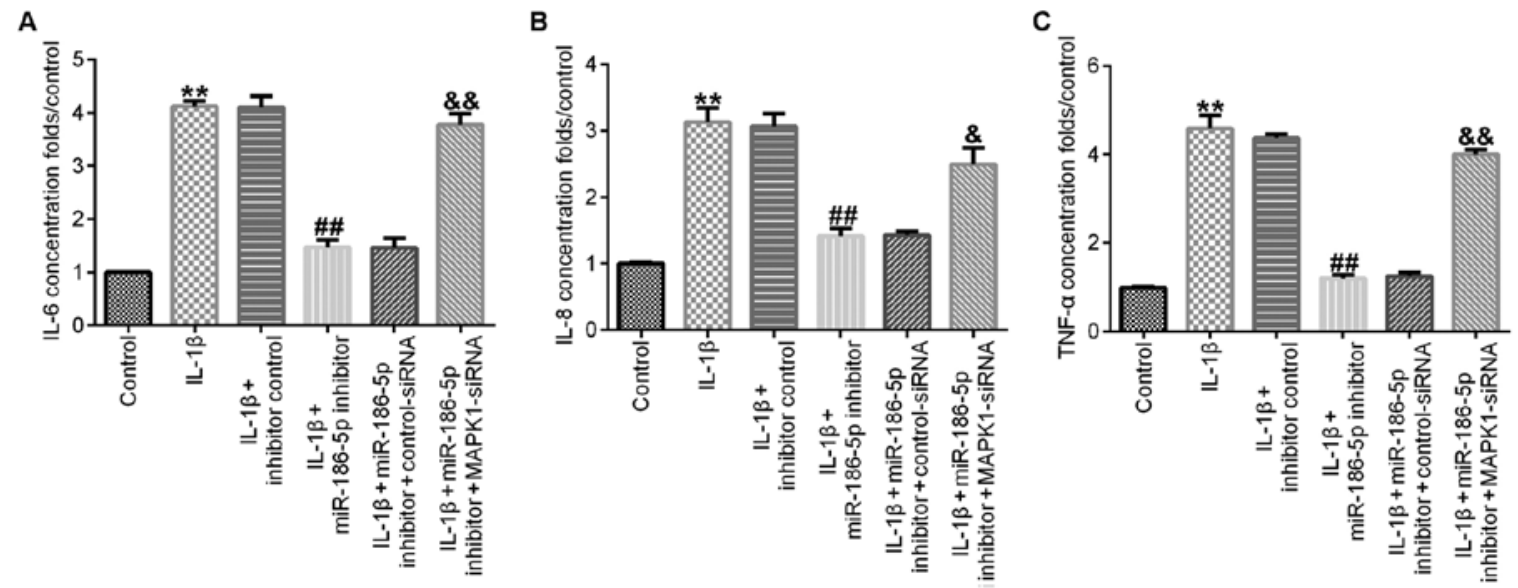

Figure 5. Effect of miR-186-5p inhibitor on IL-1 $\beta$-induced-chondrocyte inflammation. IL-1 $\beta(10 \mathrm{ng} / \mathrm{ml})$ was used to treat the transfected chondrocytes for $12 \mathrm{~h}$. The levels of inflammatory cytokines in the supernatant of CHON-001 cell culture medium were detected using ELISA. Effect of miR-186-5p inhibitor on the release of (A) IL-6, (B) IL-8 and (C) TNF- $\alpha$. ${ }^{* *} \mathrm{P}<0.01$ vs. Control; ${ }^{\# \#} \mathrm{P}<0.01$ vs. IL-1 $\beta+$ inhibitor control; ${ }^{\&} \mathrm{P}<0.05$, \&\& $\mathrm{P}<0.01$ vs. IL-1 + miR-186 inhibitor + control-siRNA. siRNA, small interfering RNA; miR-186-5p, microRNA-186-5p.
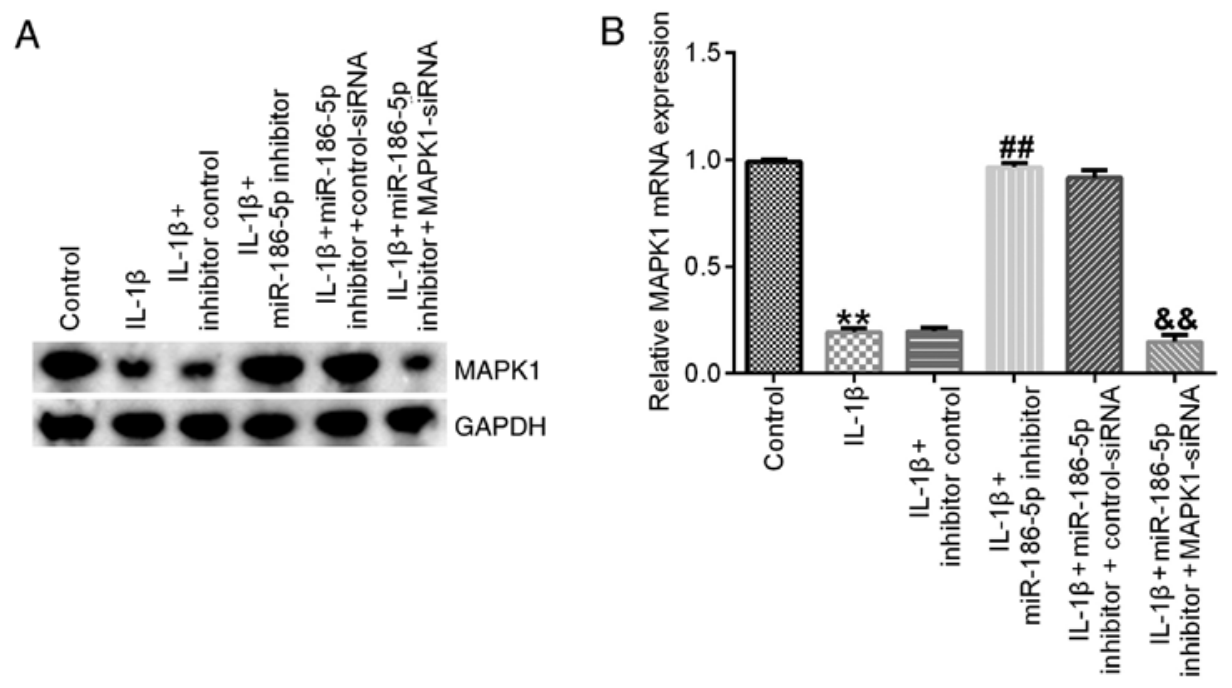

Figure 6. Effect of miR-186-5p inhibitor on MAPK1 expression in IL-1 $\beta$-induced-chondrocytes. IL-1 $\beta$ (10 ng/ml) was used to treat the transfected chondrocytes for $12 \mathrm{~h}$. Effect of miR-186 inhibitor on the (A) protein and (B) mRNA expression levels of MAPK1 in IL-1 3 -induced-chondrocytes. ${ }^{* *} \mathrm{P}<0.01 \mathrm{vs}$. Control; ${ }^{\# \#} \mathrm{P}<0.01$ vs. IL-1 $\beta$ + inhibitor control; ${ }^{\& \&} \mathrm{P}<0.01$ vs. IL-1 $\beta$ + miR-186 inhibitor + control-siRNA. miR-186-5p, microRNA-186-5p; siRNA, small interfering RNA.

miR-146a are abnormally expressed in OA and serve important roles in the pathological processes of OA (36).

The present study identified that in chondrocytes administrated IL-1 $\beta$, miR-186-5p expression was upregulated. This aberrant expression suggested that miR-186-5p may regulate the inflammatory response in chondrocytes. miR-186-5p is tumor specific, and it serves a carcinogenic or inhibitory role in different tumors $(19,21-23)$. miR-186-5p has different effects on the regulation of apoptosis in multiple types of cells or under varying conditions $(16,17,24,37)$. For example, miR-186-5p promotes apoptosis in an oxygen and glucose deprivation/reperfusion cell model (16), while miR-186-5p attenuates high glucose-induced apoptosis by regulating Toll-like receptor 3 in cardiomyocytes (37). Inhibition of miR-186-5p contributes to high glucose-induced cytotoxicity and apoptosis in AC16 cardiomyocytes (17). Moreover, miR-186 has been reported to inhibit primary mouse chondrocyte apoptosis (24). The present study also investigated the effect of miR-186-5p on the inflammatory injury of chondrocytes induced by IL-1 $1 \beta$. Contrary to previous findings that miR-186 upregulation inhibits chondrocyte apoptosis (24), the present results suggested that the miR-186-5p inhibitor suppressed chondrocyte apoptosis induced by IL-1 $\beta$. This opposite result may be due to the different environmental conditions of the chondrocytes. The previous study focused on investigating the effect of miR-186 on primary mouse chondrocyte apoptosis (24), while the current study examined the effects of miR-186-5p on IL-1 $\beta$ induced human chondrocyte cell (CHON-001) apoptosis. This controversy requires additional in-depth study.

The present results indicated that the miR-186-5p inhibitor repressed the inflammatory response in IL- $1 \beta$ induced CHON-001 cells, suggesting that a treatment strategy for OA may be the downregulation of miR-186-5p. Moreover, the present findings demonstrated that miR-186-5p may 
negatively regulate MAPK1 expression in the inflammatory response of chondrocytes, ultimately affecting OA. It is worth noting that IL-1 $\beta$ can induce production of inflammatory cytokines, such as IL- 6 and TNF- $\alpha$, by activating p38 MAPK signaling in chondrocytes $(38,39)$. Park et al $(38)$ reported that IL-1 $\beta$-induced MAPKs activation in SW1353 chondrocytes, while Sun et al (40) revealed that IL-1 $\beta$ treatment significantly activated the $\mathrm{p} 38$, JNK and ERK pathway in primary chondrocytes. However, the present study demonstrated IL-1 $\beta$ inhibited MAPK1 expression in CHON-001 cell line, and this effect was reversed by miR-186-5p inhibitor. In fact, CHON-001 has different features from the primary chondrocytes (41). The present study only used the CHON-001 cell line, and $>1$ cell line, such as primary chondrocytes, should be included in future studies to further validate the current results; this was a limitation of the present study. Moreover, chondrocytes may change their phenotype during culturing, and whether CHON-001 cells remained as chondrocytes was not identified in the current study, which was another limitation.

In conclusion, the present study used IL-1 $\beta$ to stimulate human inflammatory chondrocytes in vitro, and it was identified that upregulated miR-186-5p may regulate the inflammatory response. Furthermore, it was demonstrated that suppression of miR-186-5p could treat OA by increasing MAPK1 expression.

\section{Acknowledgements}

Not applicable.

\section{Funding}

This study was supported by the Sanming Project of Medicine in Shenzhen (grant no. SZSM201612019), the Shenzhen Key Laboratory of Digital Surgical Printing Project (grant no. ZDSYS201707311542415) and the Southern Medical University Clinical Start-up Fund (grant no. LC2016ZD036).

\section{Availability of data and materials}

The datasets used and/or analyzed during the current study are available from the corresponding author on reasonable request.

\section{Authors' contributions}

QL contributed to the study design, the data collection, data interpretation and the manuscript preparation. MW, GF, KL, WC and LL contributed to the data collection, the statistical analysis and the data interpretation. XL, JW and YC contributed to the manuscript preparation and statistical analysis, data interpretation and literature search. All authors read and approved the final manuscript.

\section{Ethics approval and consent to participate}

Not applicable.

\section{Patient consent for publication}

Not applicable.

\section{Competing interests}

The authors declare that they have no competing interests.

\section{References}

1. Xia B, Chen D, Zhang J, Hu S, Jin H and Tong P: Osteoarthritis pathogenesis: A review of molecular mechanisms. Calcif Tissue Int 95: 495-505, 2014.

2. Glyn-Jones S, Palmer AJ, Agricola R, Price AJ, Vincent TL, Weinans H and Carr AJ: Osteoarthritis. Lancet 386: 376-387, 2015.

3. Zhang W, Zhong B, Zhang C, Luo $\mathrm{C}$ and Zhan Y: miR-373 regulates inflammatory cytokine-mediated chondrocyte proliferation in osteoarthritis by targeting the $\mathrm{P} 2 \mathrm{X} 7$ receptor. FEBS Open Bio 8: 325-331, 2018.

4. Liu Q, Zhang X, Dai L, Hu X, Zhu J, Li L, Zhou C and Ao Y: Long noncoding RNA related to cartilage injury promotes chondrocyte extracellular matrix degradation in osteoarthritis. Arthritis Rheumatol 66: 969-978, 2014.

5. Sun T, Yu J, Han L, Tian S, Xu B, Gong X, Zhao Q and Wang Y: Knockdown of long non-coding RNA RP11-445H22.4 alleviates LPS-induced injuries by regulation of MiR-301a in osteoarthritis. Cell Physiol Biochem 45: 832-843, 2018.

6. He W and Cheng Y: Inhibition of miR-20 promotes proliferation and autophagy in articular chondrocytes by PI3K/AKT/mTOR signaling pathway. Biomed Pharmacother 97: 607-615, 2018.

7. Towler BP, Jones CI and Newbury SF: Mechanisms of regulation of mature miRNAs. Biochem Soc Trans 43: 1208-1214, 2015.

8. Li N, Pan X, Zhang J, Ma A, Yang S, Ma J and Xie A: Plasma levels of miR-137 and miR-124 are associated with Parkinson's disease but not with Parkinson's disease with depression. Neurol Sci 38: 761-767, 2017.

9. Le TT, Swingler TE, Crowe N, Vincent TL, Barter MJ, Donell ST, Delany AM, Dalmay T, Young DA and Clark IM: The microRNA-29 family in cartilage homeostasis and osteoarthritis. J Mol Med (Berl) 94: 583-596, 2016.

10. Endisha H, Rockel J, Jurisica I and Kapoor M: The complex landscape of microRNAs in articular cartilage: Biology, pathology, and therapeutic targets. JCI Insight 3: e121630, 2018

11. Swingler TE, Niu L, Smith P, Paddy P, Le L, Barter MJ, Young DA and Clark IM: The function of microRNAs in cartilage and osteoarthritis. Clin Exp Rheumatol 37 (Suppl 120): S40-S47, 2019.

12. Akhtar N, Rasheed Z, Ramamurthy S, Anbazhagan AN, Voss FR and Haqqi TM: MicroRNA-27b regulates the expression of matrix metalloproteinase 13 in human osteoarthritis chondrocytes. Arthritis Rheum 62: 1361-1371, 2010.

13. Rousseau JC, Millet M, Croset M, Sornay-Rendu E, Borel O and Chapurlat R: Association of circulating microRNAs with prevalent and incident knee osteoarthritis in women: The OFELY study. Arthritis Res Ther 22: 2, 2020.

14. Malemud CJ: MicroRNAs and osteoarthritis. Cells 7: 92, 2018.

15. Liu X, Zhou X, Chen Y, Huang Y, He J and Luo H: miR-186-5p targeting SIX1 inhibits cisplatin resistance in non-small-cell lung cancer cells (NSCLCs). Neoplasma 67: 147-157, 2020.

16. Wang R, Bao H, Zhang S, Li R, Chen L and Zhu Y: miR-186-5p promotes apoptosis by targeting IGF-1 in SH-SY5Y OGD/R model. Int J Biol Sci 14: 1791-1799, 2018.

17. Jiang J, Mo H, Liu C, Wu B, Wu Z, Li X, Li T, He S, Li S, You $\mathrm{Q}$, et al: Inhibition of miR-186-5p contributes to high glucose-induced injury in AC16 cardiomyocytes. Exp Ther Med 15: 627-632, 2018.

18. Xie Z, Li X, Chen H, Zeng A, Shi Y and Tang Y: The lncRNA-DLEU2/miR-186-5p/PDK3 axis promotes the progress of glioma cells. Am J Transl Res 11: 4922-4934, 2019.

19. Shan Y and Li P: Long intergenic non-protein coding RNA 665 regulates viability, apoptosis, and autophagy via the MiR-186-5p/MAP4K3 axis in hepatocellular carcinoma. Yonsei Med J 60: 842-853, 2019.

20. Jin C, Zhao W, Zhang Z and Liu W: Silencing circular RNA circZNF609 restrains growth, migration and invasion by up-regulating microRNA-186-5p in prostate cancer. Artif Cells Nanomed Biotechnol 47: 3350-3358, 2019

21. Feng H, Zhang Z, Qing X, French SW and Liu D: miR-186-5p promotes cell growth, migration and invasion of lung adenocarcinoma by targeting PTEN. Exp Mol Pathol 108: 105-113, 2019. 
22. Zhang Z, Zhang W, Mao J, Xu Z and Fan M: miR-186-5p functions as a tumor suppressor in human osteosarcoma by targeting FOXK1. Cell Physiol Biochem 52: 553-564, 2019.

23. Dong S, Wang R, Wang H, Ding Q, Zhou X, Wang J, Zhang K, Long Y, Lu S, Hong T, et al: HOXD-AS1 promotes the epithelial to mesenchymal transition of ovarian cancer cells by regulating miR-186-5p and PIK3R3. J Exp Clin Cancer Res 38: 110, 2019.

24. Zeng L, Tian XY, Huang XY, He LL and Xu F: microRNA-186 inhibition of PI3K-AKT pathway via SPP1 inhibits chondrocyte apoptosis in mice with osteoarthritis. J Cell Physiol 234 6042-6053, 2019.

25. Wang X, Fan J, Ding X, Sun Y, Cui Z and Liu W: Tanshinone I inhibits IL-1 $\beta$-induced apoptosis, inflammation and extracellular matrix degradation in chondrocytes $\mathrm{CHON}-001$ cells and attenuates murine osteoarthritis. Drug Des Devel Ther 13: 3559-3568, 2019.

26. Yang $\mathrm{X}$, Zhang Q, Gao Z, Yu C and Zhang L: Baicalin alleviates IL-1 $\beta$-induced inflammatory injury via down-regulating miR-126 in chondrocytes. Biomed Pharmacother 99: 184-190, 2018.

27. Yang Q, Zhou Y, Cai P, Fu W, Wang J, Wei Q and Li X: Downregulation of microRNA-23b-3p alleviates IL-1 $\beta$-induced injury in chondrogenic CHON-001 cells. Drug Des Devel Ther 13: 2503-2512, 2019.

28. Xiao $\mathrm{H}$ and Liu Z: Effects of microRNA-217 on high glucose-induced inflammation and apoptosis of human retinal pigment epithelial cells (ARPE-19) and its underlying mechanism. Mol Med Rep 20: 5125-5133, 2019.

29. Zhang J, Zhang Z, Shu B, Cui G and Zhong G: Cytotoxic and apoptotic activity of the novel harmine derivative ZC-14 in Sf9 cells. Int J Mol Sci 19: 811, 2018.

30. Livak KJ and Schmittgen TD: Analysis of relative gene expression data using real-time quantitative PCR and the 2(-Delta Delta C(T)) method. Methods 25: 402-408, 2001

31. Lei GH, Gao SG, Li KH, Zeng KB and Li LJ: Correlation of substance $\mathrm{P}$ and interleukin-1 beta with pathogenesis of human osteoarthritis. J Clin Rehabil Tissue Eng Res 12:7237-7240, 2008
32. Yu C, Chen WP and Wang XH: MicroRNA in osteoarthritis. J Int Med Res 39: 1-9, 2011.

33. Wu C, Tian B, Qu X, Liu F, Tang T, Qin A, Zhu Z and Dai K MicroRNAs play a role in chondrogenesis and osteoarthritis (Review). Int J Mol Med 34: 13-23, 2014.

34. Sondag GR and Haqqi TM: The role of MicroRNAs and their targets in osteoarthritis. Curr Rheumatol Rep 18: 56, 2016.

35. Cong L, Zhu Y and Tu G: A bioinformatic analysis of microRNAs role in osteoarthritis. Osteoarthritis Cartilage 25: 1362-1371, 2017.

36. Nugent M: MicroRNAs: Exploring new horizons in osteoarthritis. Osteoarthritis Cartilage 24: 573-580, 2016.

37. Liu Y, Zheng W, Pan Y amd Hu J: Low expression of miR-186-5p regulates cell apoptosis by targeting toll-like receptor 3 in high glucose-induced cardiomyocytes. J Cell Biochem 120: 9532-9538, 2019.

38. Park C, Jeong JW, Lee DS, Yim MJ, Lee JM, Han MH, Kim S, Kim HS, Kim GY, Park EK, et al: Sargassum serratifolium extract attenuates interleukin-1 $\beta$-induced oxidative stress and inflammatory response in chondrocytes by suppressing the activation of NF-kB, p38 MAPK, and PI3K/Akt. Int J Mol Sci 19: 2308, 2018.

39. Ashraf S, Cha BH, Kim JS, Ahn J, Han I, Park H and Lee SH: Regulation of senescence associated signaling mechanisms in chondrocytes for cartilage tissue regeneration. Osteoarthritis Cartilage 24: 196-205, 2016.

40. Sun FF, Hu PF, Xiong Y, Bao JP, Qian J and Wu LD: Tricetin protects rat chondrocytes against IL- $1 \beta$-induced inflammation and apoptosis. Oxid Med Cell Longev 2019: 4695381, 2019.

41. Zignego DL, Hilmer JK, Bothner B, Schell WJ and June RK Primary human chondrocytes respond to compression with phosphoproteomic signatures that include microtubule activation. J Biomech 97: 109367, 2019.

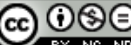

This work is licensed under a Creative Commons Attribution-NonCommercial-NoDerivatives 4.0 International (CC BY-NC-ND 4.0) License. 